ever it is in its absolute nature, it is something that renders the pulmonary nervous system unduly irritable and impressible.

This morbid sensitiveness of the pulmonary nervous system would appear to be due, in a large number of cases, to something that has organically damaged it, something that has damaged that surface to which its perceptive portion is dis tributed; for I think it will be found that in the majority of those cases in which the excitants of the attacks are stimuli admitted into the air passages, the original cause of the disease has been something organically affecting the bronchial mucous membrane-catarrhal bronchitis, measles, whooping cough. In these diseases the bronchial mucous membrane is the seat of inflammation, often intense and prolonged, and in two instances specific; and it is probable that some organic although inappreciable change has been wrought in it, producing a moribid exaltation of its sensibility to which the tendency to spasms is immediately due, according to that law of the organisation of the bronchial tubes to which I have referred in a naper on the "Absolute Nature of Asthma" in the Medico Chirurgical Review for July 1858. At any rate, in those cases in which the tendency to asthma is manifestly dependent on organic bronchial disease (as in asthma accompanying chronic bronchitis), the provocatives of the paroxysms are preeminently stimuli applied to the bronchial surface-smoke, fog, cold, etc. If then this is so, the converse is probably true,-if in asthma depending on organic bronchial disease the excitants of the attacks are stimuli applied to the bronchial surface, then, in those cases where the excitants of the attacks are stimuli applied to the bronchial surface, the asthma probably depends on organic bronchial discase.

But is this always so? Probably not. In cases of ipecacuan. asthma the excitant of the paroxysm is something applied to the bronchial mucous membrane, but there is nothing in the history of these cases to imply that this surface has ever been the seat of organic disease. The same in cases of hay-asthma.

While, then, the induction of spasm by bronchial stimuli furnishes a presumption that the asthma is due to some cause that has organically injured the bronchial mucous membrane, it does not furnish a proof of it, -in most cases it probably is so, in some not. And I think we may go a step further, and say, that where the mucous membrane exhibits a general irritability, where a great number and variety of irritants are capable of producing the asthma, there the original cause is something that has damaged the mucous membrane; where, on the other hand, the membrane exhibits a special irritability, where the irritant is specific and single, there is no such antecedent organic lesion. In the asthma of chronic bronchitis, for example, a multitude of irritants inbaled will give rise to the spasm: in hay and ipecacuan-asthma, on the other hand, the source of offence is single and specific. In the one case the cause of the asthma is something that has happened to the individual during his life, and the asthmatic tendency is acquired; in the other the cause is innate, and the tendency inherent.

But is it probable that there is some organic peculiarity in the lungs of all asthmatics? Certainly not. In a large number of cases there is not the slightest warrant for entertaining such a supposition. Take, for example, a case of emotional asthma such as the following:-A gentleman who has never suffered from any lung affection, and who is at the time in perfect health, is suddenly seized with difficulty of breathing, which proves to be spasmodic asthma, in consequence of ex treme alarm from thinking that he has administered poison by mistake. His lungs were perfectly sound; there was no history of any pulmonary affection in his case; and he never suffered from dyspncea under any other circumstances, either before or since. Horeover, the exciting cause was one not appealing to the lungs, but to the nervous system. In hayasthma, too, there is generally no history of previous lung disease, and in every part of the year, except in the hay-season, the lungs give the most positive evidence of their anatomical and physivlogical soundness.

What, then, is the cause of the asthma in these cases? I do not see that we can say anything more definite than that it consists in the asthmatic tenclency itself; in that special irritability of the pulmonary nervous system (as in the case of ipecacuan asthma), or that general irritability of the whole nervous system (as in emotional asthma, etc.), which constitutes the asthmatic idiosyncrasy with which the individual was born.

That in some cases a congenital asthmatic tendency does exist is strongly implied, I think we may say positively proved, by the undoubted hereditariness of the disease: in some families asthma is as much the disease as gout is in others. I have lately had under my care a gentleman whose father, pa. ternal grandmother, and two paternal uncles, as well as himself, were asthmatic. Now, there is no doubt what is inherited must be congenital-inborn.

But, Is any congenital peculiarity necessary? No; there appears to be no reason that a person may not become asthmatic, that the tendency to the disease may not be acquired, indeed, evidence as positive as can be imagined for believing that it may, that an asthmatic may at one time have differed in no respect from others, but that the tendency to his disease may have been engrafted on him by something that has happened to him. For example, the case of asthma as a sequela of measles, which I instanced just now. It is not conceivable that all the children whom this disease, or whooping-cough, leaves asthmatic, had any antecedent peculiarity. In no respect do they seem to differ from other cases, except that the disease from which the asthma dates has generally been of unusual severity.

It would appear, then, that in respect to causation, all cases of asthma may be broadly divided into two groups :-

1. Cases in which the essential cause of the disease-that which constitutes the individual an asthmatic-is some organic lesion, possibly not appreciable, either in the bronchial tubes, or in some part physiologically connected with the bronchial tubes.

2. Cases in which any organic lesion is not only inappreciable, but non.existent; in which the tendency to asthma is due to something from within, not from without; in which the essential cause of the disease is a congenital, and possibly inherited, idiosyncrasy.

I steer, therefore, a mildle course between those who say that asthma always has at the root of it some organic disease within the chest, and those who deny that genuine spasmodic asthma ever depends on organic lung disease, and maintain that it is always a pure neurosis. I think I have shown, on the one hand, that there are numberless cases in which the supposition of any organic cause would be purely gratuitous, and in direct contravention of all clinical evidence and pathological reasoning; and on the other, that we have every reason for believing that many cases, of the pure spasmodic variety, do really depend on some organic, though inappreciable injury that previous disease has inflicted on the lungs.

\section{CROTON OIL AS A COUNTERIRRITANT IN HYDROCEPHALUS.}

By John Watson, M.D., Southampton.

It has been my lot on several occasions to witness the successful application of this remedy to the scalp, after the setting in of most formidable symptoms. The case which first led me to its use may be outlined.

C. B., aged 2 years, a strumous-looking child, came under my notice for eczema of the scalp. The eruption, which was general and attended with copious discharge, got well under ordinary treatment. A few weeks afterwards, he had an attack of acute hydrocephalus. Leeching; cold lotions to the shaved head, calomel, and antimony, etc., were immediately resorted to, but unavailingly ; for the second stage of the disease came on. He now lay semi-comatose, with the neck extended, the eyes half-closed, and the pupils dilated. The pulse also had become slow and irregular, the respiration frequently in. terrupted with a sigh, and he had strabismus occusionally. A blister was now applied behind each ear, with no effect. Thinking it possible for his present attack to be connected with the previous condition of the scalp, as a means of best imitating the eczematous eruption, the croton oil suggested itself. With the sanction of the gentleman who was attending with me, I directed the croton oil liniment (croton oil, half a drachm; turpentine liniment, half an ounce) to be rubbed over the entire head every four hours till a plentiful crop of pustules should make their appearance; after which we soon had an amelioration of all the symptoms, and he gradually became convalescent, though he was urable to speak for several days, and could not stand alone for a considerable period.

It is now several years since the occurrence of this case, which made a deep impression upon me; for I did not remember to have seen a recovery under such unfavourable circumstances. In the same stage of the disease, whatever may have been its assumed cause, I have since adopted the 
same course, and, as far as individual experience goes, bear testimony to its efficiency. It is not so objectionable to the little patient's friends as a blister, and is at the same time more manageable; and, from the extent of surface to which it is applied, decidedly more powerfully revulsive.

\section{REMOVAL OF RINGS FROM SWOLLEN FINGERS.}

By E. Garraway, Esq., Faversham.

THE following method of removing a ring from a swollen finger, I have reason to believe, is not so generally known as it deserves. Whence I derived the idea is out of my remembrance; but the claim of its origin certainly does not rest with me.

A patient, in whom I have just had recourse to it, was suffering from acute rheumatism. The fingers were swollen; and the wedding-ring and its keeper had become imbedded, causing no little pain, and considerable alarm at the prospect of having the rings filed or broken off. The mode of pro. ceeding is this. A reel of cotton is wound evenly round, beginning on the extremity of the finger and bringing each coil into close apposition with the preceeding, until the ring is reached. A needle is then threaded with the cotton, and passed under the ring, and the thread is carefully unwound from the finger. The ring follows each coil as it is successively urrolled, and by almost impercentible degrees is brought over the knuckle and removel. Care must be taken that the cotton is wound on evenly, particularly over the protuberant and swollen linuckle, or an entanglement will occur in the unwinding. A small curved needle will pass more readily under the ring than a straight one. The process requires time, care, faith, and patience; but the reward is ample in the gratitude of the suffering patient, the signet of whose marriage bond has been saved from destruction.

\section{Transartions of 迶randtres.}

\section{SOUTH-WESTERN BRANCH.} PRESIDENT'S ADDRESS.

By C. Radclyffe Hai.s, Mi.D., Torquay. [Delivered June 23rd, 1859.]

Gentlenen,-My first duty is the very pleasing one of giving you a hearty welcome, on the part of myself and my medical brethren of Torquay, and of assuring you how highly I esteem the honour of being appointed your president for the ensuing year. To most of those whorn I have the honour of addressing, the place in which we are met together needs no introduc tion, yet on one or two points I may be permitted to allude to it. If Turquay, from its modern origin, can offer none of the historical associations in which Exeter and Plymouth are rich, as pre-eminently a health-town its youth is a great advantoge. Free from all the disqualifications of age, it has grown up into its present size within the very recent period during which alone sanitary considerations, on a large scale, have been deemed worthy of formal attention. Its principal attractions of situation, climate, and beauty, are, of course, as old as the hills over which its buildings spread; but its urban advantages are only just completed. Torquay ought now to be the model town of England, as regards sanitary arrangements. I am not sure that it is not so. Fresh air, pure water, effective drainage, all in abundance, constitute almost ail which public bodies can do to render their town healthy. Looking at the geology and general aspect of 'Torquay, a stranger would suppose it impossible for it to be otherwise than well drained by nature. Bu man has great power to thwart the beneficence of nature; and when cholera visited this place in 1849 , it pointed out accurately, as with a black line, where the drainage was imperfect. Under the government of our Local Board of Health, which, through good report and evil report, has proved of immense service to the town, all this is now rectified.

Effective drainage is impossible without an ample supply of water. From the absense of any large source of fresh water in the immediate neighbourhood, it has been necessary to obtain it from a distance of fourteen miles, on the margin of Dartmoor, at a cost to the town of between $£ 40,000$ and $£ 50,000$ This water is very pure, having trickled merely through the granite of Dartmoor; and, whether from the disintegration of the granite having given to it some minute portion of alkali, or from some other cause, it is found to be actually softer than the rain-water collected here. Heretofore we have been chary of saying much in favour of Torquay as a place of resort for patients who suffer from chronic affections of the kidneys, because, however useful in such disorders it may be to reside in a mild climate, which promotes the action of the skin, yet, as a rule, a hard calcareous water does not suit reral affections; and our spring water is very hard. Like water of this kind clsewhere, it is bright, clear, and sparkling; pleasant to the taste, and possibly not without its virtues for those whose bodies betray a want of lime: certainly not without its chemical potency out of the body; for, but for its presence, we must have suffered from lead-poisoning on a large scale. I suppose every house that has a pump is supplied with spring water through lead pipes; yet we never see any instance of lead poisoning from this cause, either slight or severe. And this is not because the water does not act upon the lead, since we find that the pipes are coated on their interior, and eventually, in places, eaten through in a worm-eaten fashion. Yet reagents shew no trace of lead in the water. Evidently the water forms an insoluble compound with the lead, which is precipitated in the shape of carbonate and hydrated oxide. Excepting water so impure, from contamination with drains, as to contain alkaline nitrates and chlorides in solution, as a general rule we know that the purer and softer the water, the more dangerous for lead; and, consequently, the immunity we have hitherto enjoyed must not, as a matter of course, be taken for granted to apply to the new water. As this, however, requires a new and distinct service, and the custom is to use iron pipes for it, the question will not be put to the test by the public. Experimentally, though it acts rather too freely upon iron, I find this new water does not dissolve lead. Torquay can now boast not only of good water in abundance, both hard and soft,- and so suit both ricketty children and gouty parents, - but it also possesses, for the external employment of water, whether fresh or sea, perhaps the finest baths in the kingdom. Erected at a cost of nearly $\$ 10,000$ these excellent baths-as I think the quict splendour of this saloon, in which, by the liberality of the directors, we are now sitting, will testify-reflect great credit on the public spirit of those private individuals who have thus deserved so well of their town.

Of the winter climate of Torquay, it is unnecessary to say one word; but respecting its summer climate, a passing remark may not be misplaced. Mr. Vivian has proved beyond all question that figures substantiate the coolness of our summer climate. Yet no one believes him ;-excepting those only who have stayed at Torquay during the summer. 'The air is always a soft air, but never an over hot air; you do not find your lips parched or your mouth dry. Of course, the direct heat of the sun in this clear atmosphere is often considerable; but on the hills, or in open places; in summer the air is soft and fresh. "I know nothing about the mildness of Torquay in the winter, because I hare never been here in the winter," said a Cheshire gentleman to me, "but I know this that it is the coolest place in England in the summer"! And, to a certain extent, it ought to be Being almost a peninsula, the same modifying influence of the sea which causes its winter-mildness, must render it cool in summer. The sea, being a worse conductor of heat than the land, cools less in winter, and heats less in summer and accordingly, the sea-breezes warm the air over the neigh bouring coast in winter, and cool the air in summer. Moreover, the adjoining land being thus cooled down by the sea air every night in summer, cannot accumulate heat during the persistence of hot dry weather as it does in inland places.

Having adverted to our obligations to Mr. Vivian on the subject of meteorology, I cannot resist referring to his recent work in editin at the cost of no inconsiderable labour, $\mathrm{Mc}$ Enery's Cavern Researches, in which the geologist will find the most interesting information respecting our world-wide celebrated Kent's Cavern, and Ossiferous Caves in general-such, for example, as the newly discovered one at Brixham, now in process of investigation under the superintendence of $\mathrm{Mr}$. Pengelly, the 'Torquay geologist par excellence.

Torquay possesses three medical institutions. The Torbay Infirmary and Dispensary, which does all that the most ad mirable institution of this kind can, has a staff of three phy sicians, three surgeons, and a House-Surgeon. The honorary officers of this institution have here, as elsewhere, the privilege of bestowing their constant charity in deeds of active exertion for the benefit of the sick and needy;-a kind of charity which in actual benefit so far transcends the mere giving of 